\title{
Calidad de los derivados lácteos producidos en la Región Amazonas, Perú
}

\section{Quality of dairy products produced of the region Amazonas, Peru}

\author{
Jhony Gonzales-Malca ${ }^{1 *}$ (D), María Abanto-López ${ }^{1}$ (D)
}

\section{RESUMEN}

El objetivo del presente trabajo fue evaluar la calidad de los productos lácteos (queso fresco, queso madurado y yogurt) en cuanto a parámetros fisicoquímicos y microbiológicos en seis provincias de la región Amazonas. Se recolectaron 135 muestras: queso fresco (45), queso madurado (46) y yogurt (44), procedentes de 27 plantas de derivados lácteos. Los resultados fueron comparados con los estándares establecidos en la Norma Técnica Peruana para leche y productos lácteos NTP 200.001-2003. Para la evaluación fisicoquímica se determinó potencial de hidrógeno $(\mathrm{pH})$, acidez ( $\mathrm{g}$ de ácido láctico /g de muestra) y humedad, parámetros químicos (proteína, grasa y energía), parámetros microbiológicos (coliformes totales, coliformes fecales, bacterias aerobias mesófilas viables, Staphylococcus aureus y enterobacterias). Para coliformes y bacterias mesófilas viables los resultados son de tipo cuantitativo, NMP/ml y UFC/ml, respectivamente. En cuanto a Staphylococcus aureus y enterobacterias se consideró la presencia o ausencia.

Palabras claves: productos lácteos, fisicoquímico, microbiológico, procesadores.

\begin{abstract}
The objective of this study was to evaluate the quality of dairy products (cheese, ripened cheese and yogurt) in terms of chemical and microbiological parameters in six provinces of the region Amazonas, at producer level. 135 samples were collected; fresh cheese (45), ripened cheese (46) and yogurt (44); from 27 dairy products plants. The results were compared with the standards established in the Peruvian Technical Standard for milk and milk products NTP 200.001-2003. For the physicochemical evaluation, hydrogen potential $(\mathrm{pH})$, acidity ( $\mathrm{g}$ of lactic acid / $\mathrm{g}$ of sample) and humidity were determined, chemical: protein, fat and energy, microbiological: total coliforms, fecal coliforms, viable mesophilic aerobic bacteria, Staphylococcus aureus and enterobacteria. For viable coliforms and mesophilic bacteria, the results are quantitative $\mathrm{NMP} / \mathrm{ml}$ and $\mathrm{CFU} / \mathrm{ml}$ respectively; as for Staphylococcus aureus and enterobacteria, the presence or absence was considered.
\end{abstract}

Keywords: dairy products, physicochemical, microbiological, producers. 


\section{INTRODUCCIÓN}

El sector productor de lácteos en la región de Amazonas se ha ido incrementando paulatinamente conforme al desarrollo ganadero de la región, pero todavía no ha alcanzado un desarrollo propiamente dicho, considerando principalmente que en el sector lácteo de la región aún existe informalidad y la resistencia al cambio por parte de los actores involucrados.

Es importante resaltar que los productos derivados nunca serán de mejor calidad que la materia prima de la que procede, debido a ello si la leche cruda es de mala calidad, no se podrá obtener ningún derivado de buena calidad (Luigi et al., 2013). Y teniendo conocimiento que la leche constituye un excelente sustrato para la proliferación de microorganismos debido a su alto contenido de nutrientes (Cristóbal y Maurtua, 2003), se deberán tomar las medidas necesarias para evitar la contaminación y proliferación de organismos a partir de la leche cruda. La leche, una vez extraída, sufre una variedad de cambios en su composición debido al incremento de microorganismos, que pueden ir desde decenas (presentes en la ubre) hasta miles vehiculados por utensilios de ordeño no higienizados; y al transcurrir las horas, pueden alcanzar a millones por mililitro. También, las enzimas presentes en la leche, como las lipasas, pueden acelerar su deterioro afectando la calidad de la materia prima, debido a ello, los especialistas han recomendado aplicar las buenas prácticas de ordeño y enfriarla lo antes posible (Gonzales, 2017).

La elaboración de derivados lácteos sólidos en la región (especialmente el queso fresco) se hace mayormente a partir de leche cruda, es decir, sin pasteurizar o sometida a calentamiento térmico ("pasteurización" incompleta), este último no provoca el efecto de eliminar patógenos; o se efectúa la pasteurización, pero el producto terminado puede contaminarse durante el empacado, transporte, mal almacenamiento, etc., y finalmente afectar la salud pública. En lo que se refiere al queso madurado, la contaminación puede darse en cualquiera de las etapas de procesamiento, pero especialmente durante la maduración (por ejemplo, si se realiza la maduración en condiciones inadecuadas). La presencia de contaminantes de diversa índole en productos lácteos se puede a prevenir aplicando las buenas prácticas de ordeño y las buenas prácticas de manufactura.

Como indicadores de calidad microbiológica se registra la presencia de aerobios mesófilos, coliformes totales, coliformes fecales, Escherichia coli y Staphylococcus aureus. Estos microorganismos, como es el caso de los aerobios mesófilos, están presentes en el queso y otros productos lácteos como consecuencia de mala higiene y manipulación. Los coliformes tanto totales como fecales y $E$. coli se consideran indicativos de contaminación fecal, por lo cual no deben estar presentes en el alimento (Carrasco, 2002). Asimismo, el Staphylococcus aureus en el queso manifiesta una gran deficiencia higiénica y representa un peligro latente como vehículo de intoxicación estafilocócica. El S. aureus se encuentra presente no sólo por el uso de leche cruda en la elaboración del queso, sino también es responsable de mastitis, la cual es una enfermedad que ocurre a nivel de glándulas mamarias infectadas del animal y están influenciadas por ambiente donde se encuentren a la hora del ordeño o mala practicas del ordeño por parte del personal debido a las condiciones sanitarias inadecuadas (Vásquez et al., 2010).

Para finalizar, conocer la calidad sanitaria de los productos lácteos a nivel productor nos permitirá implementar las medidas correctivas necesarias con el fin de garantizar que los productos sean de calidad e inocuos para la salud.

\section{MATERIAL Y MÉTODOS}

Área de estudio

La presente investigación fue realizada en seis provincias de la región Amazonas: Chachapoyas, Luya, Rodríguez de Mendoza, Bongará, Bagua y Utcubamba (Figura 1).

\section{Materiales}

Se realizó el análisis fisicoquímico y microbiológico de 135 muestras de productos lácteos: queso fresco, queso madurado y yogurt

\section{Muestras}

Se recolectaron 135 muestras: queso fresco (45), queso madurado (46) y yogurt (44), procedentes de 27 


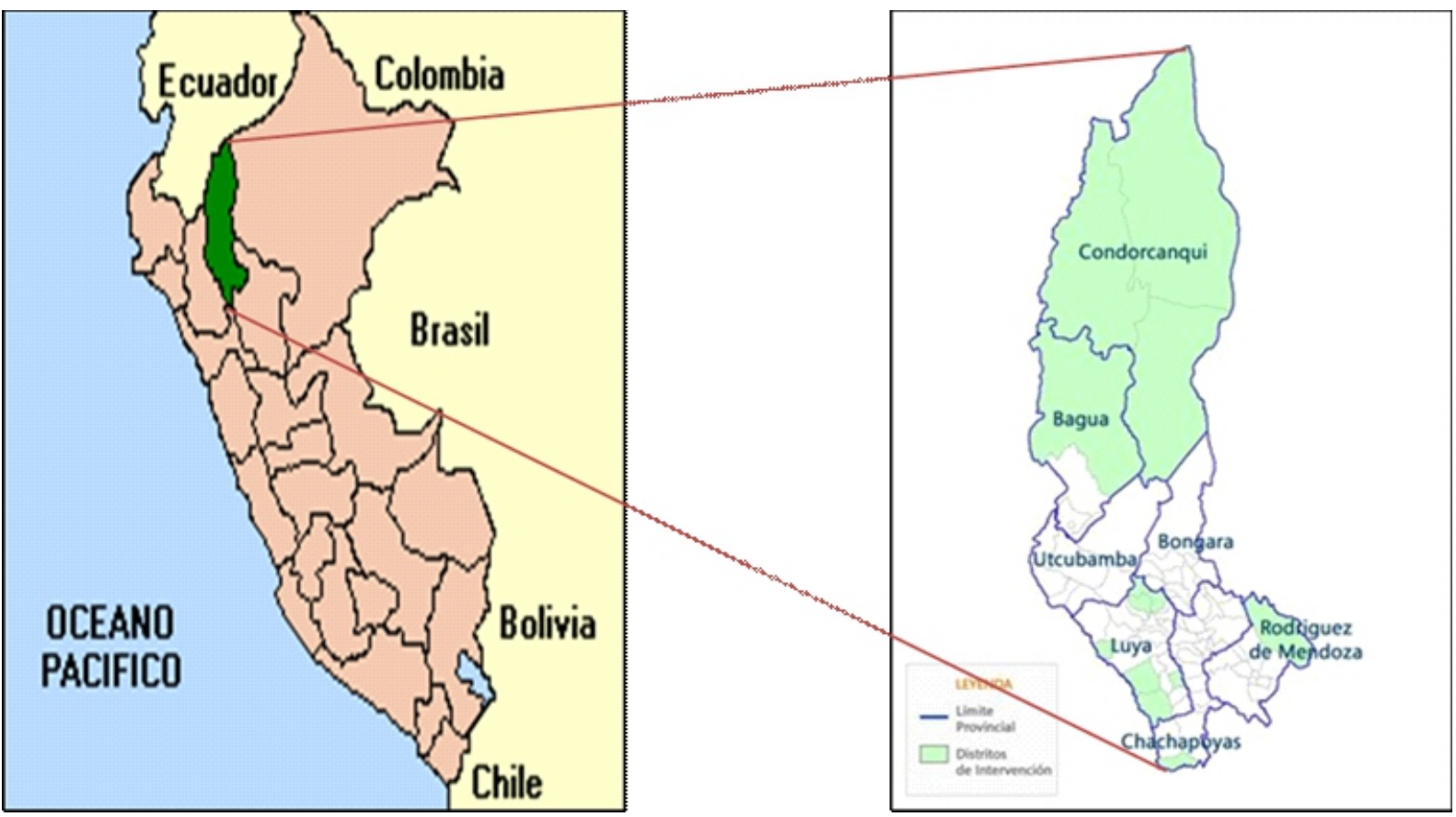

Figura 1. Mapa de ubicación del ámbito de intervención del proyecto.

plantas de derivados lácteos. La cantidad requerida de muestra para el procesamiento fue 300 gramos para cada tipo de queso y $500 \mathrm{ml}$ de yogurt. Una vez recolectadas las muestras sólidas eran colocadas en bolsas Whirl-Pak estériles, rotuladas y transportadas al laboratorio a $4^{\circ} \mathrm{C}$ (cadena de frío). A continuación, las muestras fueron fraccionadas y destinadas a los laboratorios para los análisis respectivos. Las cantidades requeridas para el análisis microbiológico, químico y físico que se necesitaron fueron muestras de $200 \mathrm{~g}, 50$ g y 50 g, respectivamente, en lo concerniente a los derivados lácteos sólidos (queso fresco y queso madurado). Asimismo, para el yogurt se utilizaron $200 \mathrm{ml}$, $150 \mathrm{ml}$ y $200 \mathrm{ml}$ para los mismos análisis.

\section{Análisis fisicoquímico}

Los análisis se realizaron en el Laboratorio de Nutrición Animal y Bromatología de Alimentos - UNTRM. $p H$

Se realizó mediante un potenciómetro marca Oakton (Modelo pH50) calibrado con solución buffer de pH 4 y solución buffer de $\mathrm{pH} 7$, con un nivel de confianza del $99.9 \%$.

\section{Humedad}

Para ello se utilizaron 50g de muestra de queso fresco o madurado en placas Petri, en cuanto al yogurt se utilizó crisol de vidrio, a continuación, se procedió a colocar las muestras en una estufa ECOCELL modelo LSIS $\mathrm{B} 2 \mathrm{~V} / \mathrm{EC} \mathrm{a} 35^{\circ} \mathrm{C}$ (yogurt) y $60^{\circ} \mathrm{C}$ (queso fresco y madurado) por un periodo de 12 a 24 horas. La humedad se calculó, a partir de la pérdida de peso de la muestra tras desecación, hasta obtener dos pesos constantes.

Acidez

Determinación de acidez total por volumetría, la acidez fue expresada como porcentaje de ácido láctico titulado con $\mathrm{NaOH}$ 0,1 N. El resultado fue expresado en $\mathrm{g}$ de ácido láctico /gramo (o ml) de muestra.

\section{Proteina}

Para la determinación se usó el método Kjeldhal basado en los procesos de digestión, dilución y destilación. Grasa

Se realizó mediante el método Soxhlet en un equipo extractor de grasa marca SLECTA(Modelo 4002842). Energía

Se realizó mediante el método de combustión.

\section{Análisis microbiológico}

Para la determinación de coliformes totales y coliformes fecales (termotolerantes) se realizó por el método de tubos múltiples o técnica del número más probable $(\mathrm{NMP} / \mathrm{ml})$ con diluciones de $10^{1}, 10^{2} \mathrm{y} 10^{3}$. Para la determinación de Staphylococcus aureus y Enterobacterias 
se realizó por siembra en placa con la técnica de siembra en estrías y los resultados se expresaron cualitativamente por presencia o ausencia. En lo que se refiere a bacterias aerobias mesófilas viables se utilizó la técnica de recuento en placa por técnica de siembra de incorporación utilizando agar Plate Count e incubado a $37^{\circ} \mathrm{C}$ por 24 a 48 horas. Los resultados fueron expresados en unidades formadoras de colonias (UFC/ml).

\section{Determinación de histamina (ug/ml)}

Para determinar la concentración de histamina se utilizó el Método UHPLC Ultra Cromatógrafo Líquido, realizado en un equipo UHPLC (Marca Agilent Technologies modelo Infinity II 1290).

\section{Determinación de proteína}

Para determinar el porcentaje de proteínas, se usó la siguiente formula:

$$
\% \text { Proteína }=\frac{\mathrm{P}_{2}}{\mathrm{P}_{0}} \times 100 \times \mathrm{F}
$$

Donde:

$\mathrm{P}_{2}=$ Nitrógeno $(\mathrm{mg})$

$\mathrm{P}_{0}=$ Peso de la muestra $(\mathrm{mg})$

$\mathrm{F}=$ Factor proteínico $(6,25$ por defecto $)$

\section{Acidez (g de ácido láctico/g de muestra)}

Para determinar la acidez, se usó la siguiente formula:

$$
\mathrm{A}=\frac{\mathrm{V} \cdot \mathrm{N} * \mathrm{Meq}}{\mathrm{M}} \times 100
$$

Donde:

$\mathrm{A}=$ Acidez en ácido láctico.

$\mathrm{V}=$ Gasto de la solución $0.1 \mathrm{de} \mathrm{NaOH}$, en $\mathrm{ml}$

$\mathrm{N}=$ Normalidad de la solución de $\mathrm{NaOH}$

$\mathrm{Meq}=$ valor del ácido láctico en mil-equivalente que es de 0,09

$\mathrm{M}=$ Peso de la muestra en gramos

\section{Humedad}

Para determinar el porcentaje de humedad, se usó la siguiente formula

$$
\% \text { humedad }=\frac{M_{1}-M_{2}}{M_{1}-M_{0}} \times 100
$$

Donde:

$\mathrm{M}_{0}=$ Masa de la placa Petri utilizada / crisol de vidrio $\mathrm{M}_{1}=$ Masa de la placa Petri o crisol de vidrio y la muestra antes de secarse.

$\mathrm{M}_{2}=$ Masa de la placa Petri o crisol de vidrio y la muestra después del secado.

\section{Análisis de datos \\ Debido a que la varianza poblacional es desconocida y el tamaño de muestra es inferior a 30 se realizó un análisis aplicando el estadístico t-Student. Este proce- dimiento permite precisar evidencias acerca del com- portamiento de los valores obtenidos en las muestras con respecto a los parámetros que establece la norma.}

\section{RESULTADOS}

Caracterización de los productos lácteos a nivel de productor

Al realizar las pruebas de hipótesis a los productos lácteos a nivel de productor en las provincias de Bongará, Chachapoyas, Luya, Rodríguez de Mendoza y Utcubamba, los resultados presentan evidencias que indican que los parámetros físicos y microbiológicos tienen valores inferiores a los establecidos en la norma NTS Nº 071-MINSA/DIGESA-V.01 (DIGESA, 2003). Esto se demuestra por medio de la obtención de valores del estadístico t-Student con probabilidades superiores a un nivel de significancia $(\alpha)$ de 0,05 , que se traducen en no significativos, indicando la aceptación de la hipótesis nula, que expresa valores de los parámetros evaluados que no exceden los límites máximos permisibles según la norma antes citada, la cual establece los criterios microbiológicos de calidad sanitaria e inocuidad para los alimentos y bebidas de consumo humano. 


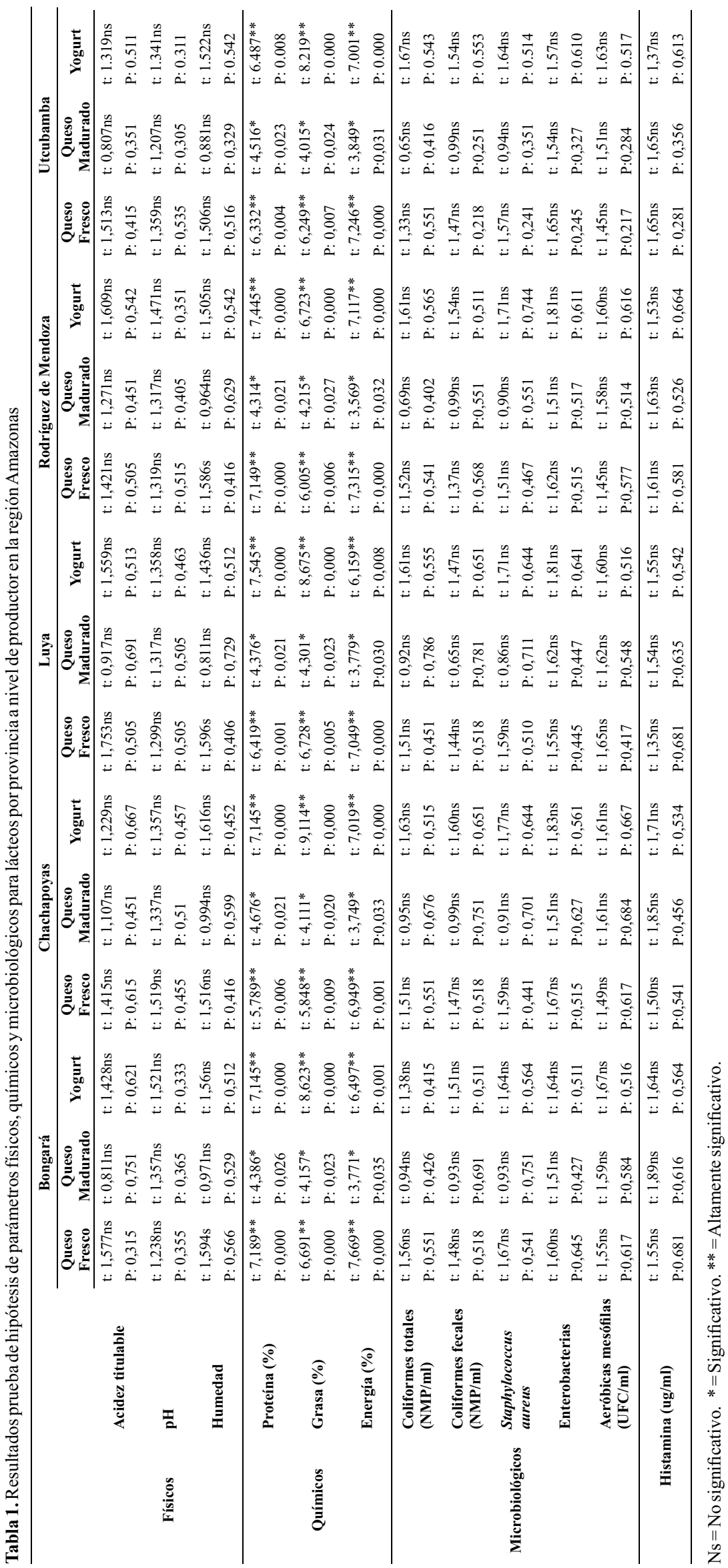

54 Rev. de investig. agroproducción sustentable 5(1): 50-57, 2021 ISSN: 2520-9760 
Con el propósito de realizar un análisis descriptivo de los parámetros químicos proteína, grasa y energía, por considerarlos los más relevantes en la situación objeto de estudio, se procedió a construir gráficos "Box Plot", los cuales permiten observar una variabilidad alta (Figura 2-4). De los gráficos se puede apreciar la variación de distribuciones de los parámetros proteína y grasa, entre provincias resaltando que la distribución es mayor (es decir, mayor dispersión) para la provincia 4 (Tabla
1). Para el parámetro energía podemos apreciar que en la provincia 4 se observa una distribución con sesgo negativo de tal forma que la mediana está más cerca del lado derecho de la caja (valores más altos), lo que implica que el $25 \%$ de las observaciones comprendidas entre el segundo y tercer cuartil ocupa un menor tramo en la escala que igual proporción de observaciones correspondiente a valores comprendidos entre el primer y segundo cuartil.

\section{Box and Whisker Plot}

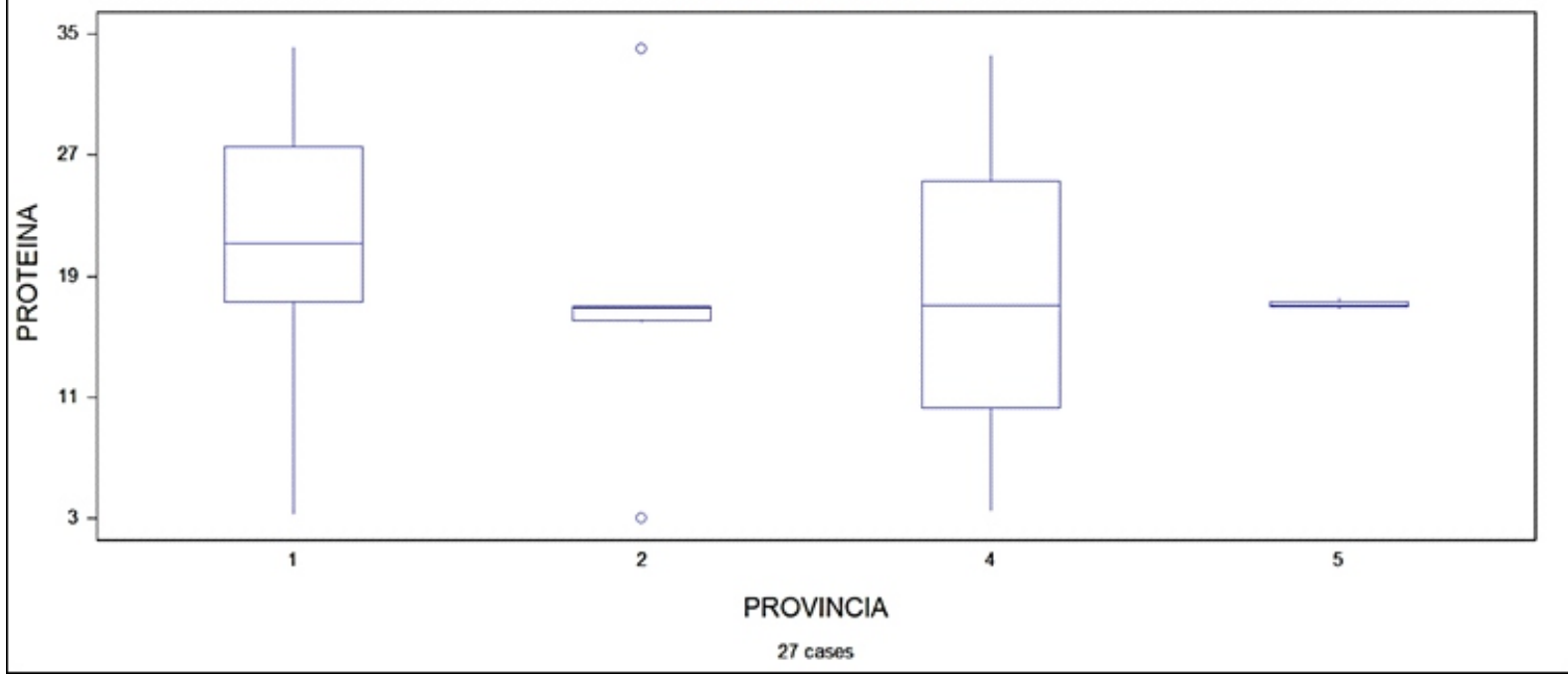

Figura 2. Provincias en función del parámetro proteína.

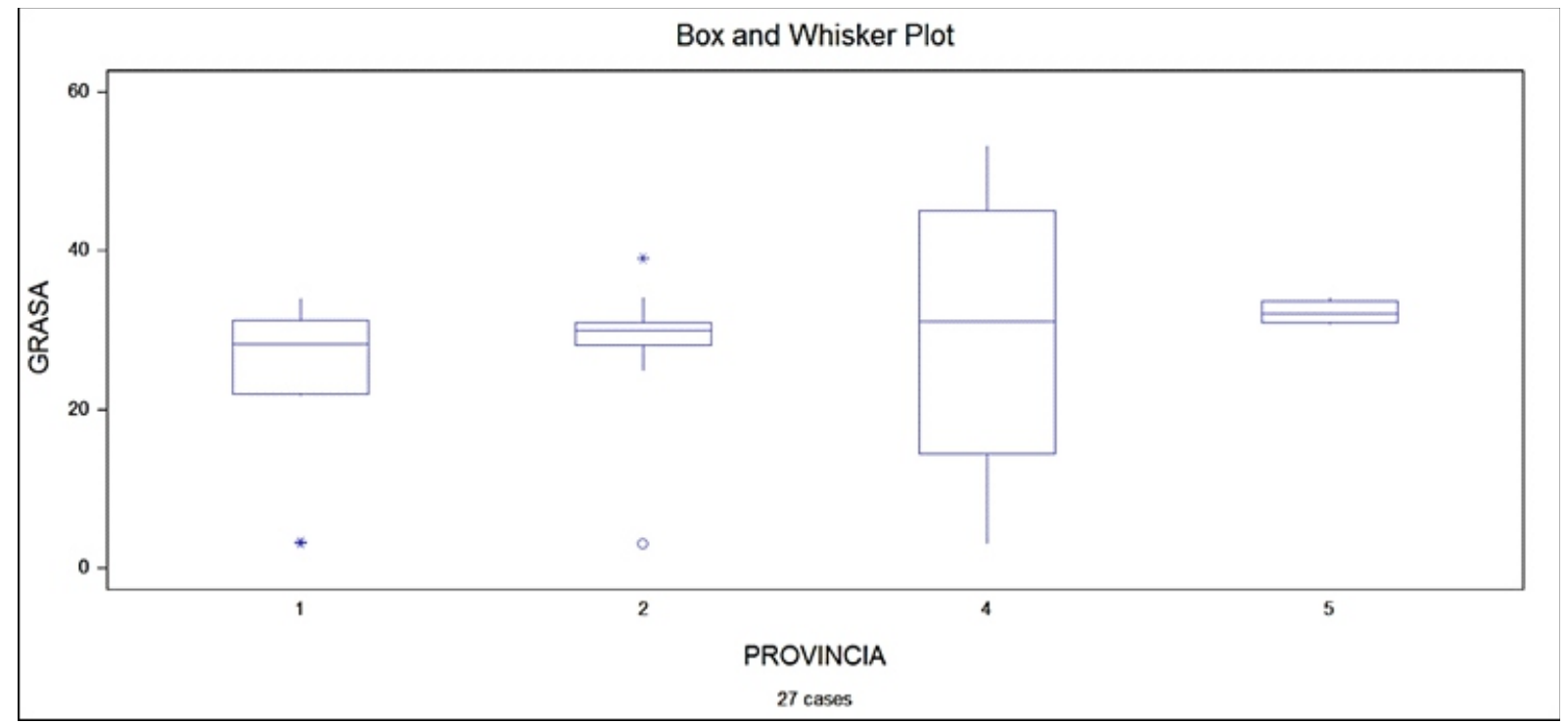

Figura 3. Provincias en función del parámetro grasa. 


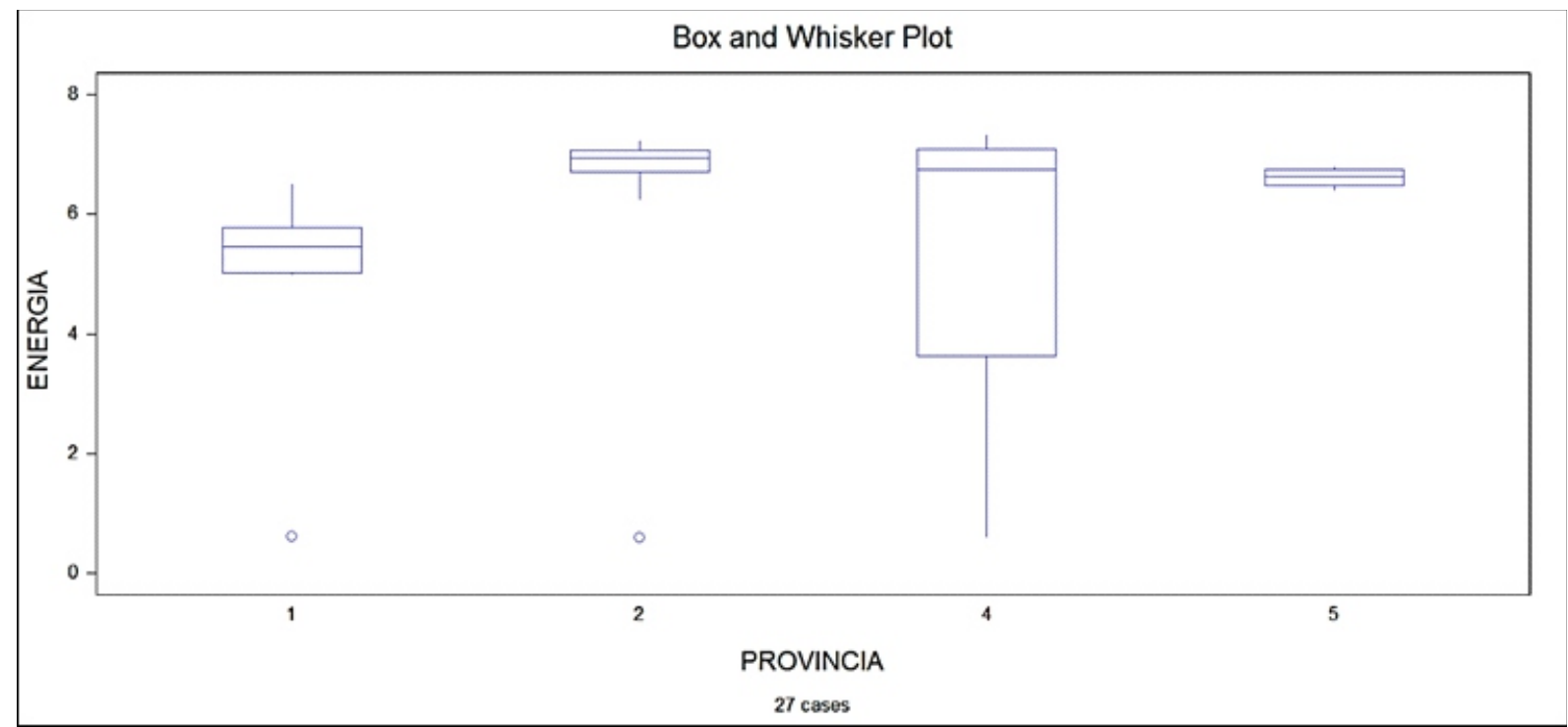

Figura 4. Provincias en función del parámetro energía.

\section{IV.DISCUSIÓN}

Condo (2016) determinó la calidad microbiológica de los quesos frescos artesanales comercializados en el mercado de Andrés Avelino Cáceres de Arequipa, donde se determinó la presencia de coliformes fecales en un promedio 538,83 NMP encontrándose en condición de aceptable, ya que el valor es menor al nivel crítico establecido en el reglamento de la leche y productos lácteos D.S N ${ }^{\circ}$ 007-2017-MINAGRI (MINAGRI, 2017). En cuanto a los resultados obtenidos en el presente trabajo para quesos fresco son similares, ya que se ha encontrado un rango que oscila entre 451 y $530 \mathrm{NMP}$ (variación poco significativa por provincia), y, por ende, la condición del producto es aceptable.

Los resultados obtenidos difieren con lo reportado por Cristóbal y Maurtua (2003) quienes al evaluar la carga microbiana de 39 muestras de quesos frescos artesanales adquiridas en siete mercados municipales de Lima, encontraron que la carga microbiana del $97,4 \%$ de las muestras estuvo por encima de los valores máximos permitidos en la normativa peruana: coliformes totales, coliformes fecales, E. coli y $S$. aureus. Si bien es cierto, que en cuanto al análisis microbiológico los resultados obtenidos en el presente trabajo se encuentran dentro de lo aceptable en comparación con lo reportado en Lima, esto podría deberse a que durante el transporte del producto al mercado no se efectúa en las condiciones higiénicas adecuadas.

Castillo (2014) estudió la "Viabilidad de probióticos en yogur batido durante su almacenamiento en refrigeración", y para ello determinó la calidad sanitaria de los productos elaborados. Así, el primer día de su elaboración se controló la presencia de Coliformes totales, Staphylococcus aureus, Escherichia coli, mohos y levaduras, obteniendo como resultado la ausencia de todos ellos, lo que permitió determinar que los productos cumplieron con los parámetros sanitarios establecidos. Por otro lado, en el presente trabajo se encontraron niveles aceptables por la normativa peruana de contaminación microbiológica (presencia de coliformes, mesófilas viables) en yogurt. La diferencia se puede deber principalmente a que en el trabajo desarrollo por Castillo se aplicaron las buenas prácticas de manufactura.

\section{CONCLUSIONES}

Conforme a los resultados expuestos en base a los análisis realizados y a la prueba estadística aplicada podemos indicar que los productos lácteos (queso fresco, queso madurado y yogurt) a nivel de productor se encuentran en condición de aceptable, sin, cabe indicar que aunque los resultados microbiológicos se encuentren dentro del rango de aceptabilidad confor- 
me a lo establecido por la norma, los microorganismos encontrados en los productos lácteos nos indican que se produjo la contaminación por manipulación no higiénica (desde la materia prima o durante el procesamiento) y/o un almacenamiento inadecuado (por ejemplo no efectuar correctamente la cadena de frío).

\section{CONTRIBUCIÓN DE LOS AUTORES}

Todos los autores participaron en la conceptualización, metodología, investigación, redacción del manuscrito inicial, revisión bibliográfica, y en la revisión y aprobación del manuscrito final.

\section{CONFLICTO DE INTERESES}

Los autores declaran no tener conflicto de intereses.

\section{REFERENCIAS BIBLIOGRÁFICAS}

Castillo, C. M. J. 2014. Viabilidad de probióticos en yogur batido durante su almacenamiento en refrigeración. Tesis de Maestría. Universidad Nacional Agraria de La Molina. Lima (Perú).

Condo, P. D. M. 2016. Determinación de la calidad bacteriológica en quesos frescos artesanales que se expenden en el mercado Andrés Avelino Cáceres en la ciudad de Arequipa, Mayo Agosto 2015. Tesis de Grado. Uniersidad Nacional de San Agustín de Arequipa. Arequipa (Perú).

Cristóbal, D. R. L. y T. D. J. Martua. 2003. “Evaluación bacteriológica de quesos frescos artesanales comercializados en Lima, Perú, y la supuesta acción bactericida de Lactobacillus spp". Revista Panamericana de Salud Pública 14: 158-164.

DIGESA (Dirección General de Salud Ambiental). 2003. "NTS N071 - MINSA/DIGESA-v.01 Norma sanitaria que establece los criterios microbiológicos de calidad sanitaria e inocuidad para los alimentos y bebidas de consumo humano". Lima (Perú).

Gonzales E. C. 2017. Guía para elaborar un manual de buenas prácticas de manufactura (BPM) y programa de higiene y saneamiento (PHS) para pequeños productores de queso fresco. Lima (Perú): OPS y MINSA.

Luigi, T., L. Rojas, y O. Valbuena. 2013. "Evaluación de la calidad higiénico-sanitaria de leche cruda y pasteurizada expendida en el estado Carabobo, Venezuela". Salus 17 (1): 25-33.

MINAGRI (Ministerio de Agricultura y Riego). 2017. “D.S No 007-2017-MINAGRI. Decreto supremo que aprueba el Reglamento de la leche y productos lácteos". Lima (Perú).

Vásquez, N., L. Duran, C. Sánchez, y I. Acevedo. (2012). "Evaluación de las características fisicoquímicas y microbiológicas del queso blanco a nivel de distribuidores, estado Lara, Venezuela”. Zootecnia Tropical 30 (3): 217223. 